\title{
OSCILLATION OF WATER MASS APPEARING IN SQUARE AND CIRCULAR SURFACE AERATION TANKS
}

\author{
HITOSHI TAKASE, HAJIME UNNO AND TAKASHI AKEHATA \\ Department of Environmental Chemistry and Engineering, Tokyo Institute of Technology, Yokohama 227
}

\section{Introduction}

The appearance of liquid oscillation in surface aeration tanks of circular type has been pointed out ${ }^{11}$. The authors observed surface oscillations of liquid in a square surface aeration tank as well. These oscillations were due to the agitation of liquid mass by the aerator. The oscillation seemed to be a kind of standing wave and occurred under restricted conditions. The purpose of the present paper is to indicate some features of these phenomena.

\section{Experimental}

The experimental apparatus is shown in Fig. 1. Tanks of two types, i.e. square and circular, were used as aeration basins. The aerators used were of disk turbine type. The turbine impeller was fitted with six blades. Experimental conditions are summarized in Table 1.

\section{Results and Discussion}

With increase of impeller speed a distinct oscillation of the water surface appeared and some oscillation characteristics, such as oscillation pattern and frequency, remained constant though the intensity increased somewhat with impeller speed. Above an increased impeller speed the oscillation ceased, probably due to the lack of energy for continuing the oscillation since the impeller splashed almost all water mass around the impeller into droplets. Therefore, the oscillation phenomena were sustained by input energy from the aerator.

Figure 2 shows typical standing waves observed in the square and circular tanks. Dotted lines in the schematic plan views mean the node of standing waves. At the tank wall the waves seem to have a maximum oscillation, i.e. the loop of the waves. The oscillation frequencies obtained experimentally are summarized in Tables $\mathbf{2}$ and $\mathbf{3}$.

The ranges of impeller speed where standing waves in square tank Fig. 2 (a) were observed were 13.0 $13.5 \mathrm{rps}, 2.83-6.66 \mathrm{rps}$ and $2.33-3.17 \mathrm{rps}$ for impeller

Received February 3, 1982. Correspondence concerning this article should be addressed to H. Takase, now at Dept. of Chem. Eng., Toyama Univ., Takaoka 933. diameters $0.03 \mathrm{~m}, 0.12 \mathrm{~m}$ and $0.18 \mathrm{~m}$, respectively. Figure 3 shows the experimental results for the frequency, which seems to increase with $H / W$ and reach a constant value. This relation may be explained as follows.

Regular surface oscillation never appeared till the flow in the tank became highly turbulent. Therefore, the bulk liquid flow at the beginning of oscillation would be a potential flow. Granting this assumption, the standing water waves observed in the tanks are expressed by Laplace's equation, i.e.,

$$
\nabla^{2} \phi=0
$$

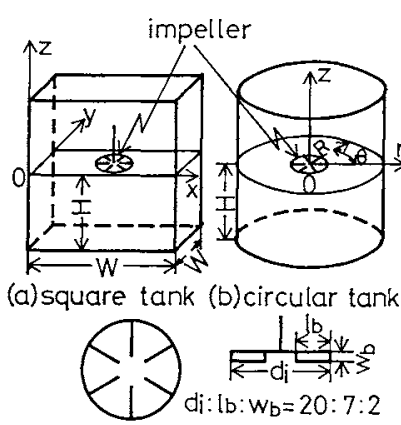

(c) impeller

Fig. 1 Experimental apparatus

Table 1 Experimental conditions

\begin{tabular}{ccccl}
$\begin{array}{c}\text { [Square tank] } \\
W[\mathrm{~m}]\end{array}$ & $d_{i}[\mathrm{~m}]$ & $n[\mathrm{rps}]$ & $H[\mathrm{~m}]$ & $H s_{0}[\mathrm{~m}]$ \\
\hline 0.2 & 0.03 & $5.00-46.7$ & $0.075-0.2$ & 0 \\
& & & & 0.01 \\
& 0.06 & $1.67-16.7$ & & 0.02 \\
0.3 & 0.03 & $5.00-46.7$ & $0.075-0.3$ & 0 \\
& 0.06 & $1.67-16.7$ & & 0.01 \\
& 0.12 & $0.83-6.67$ & & 0.02 \\
0.5 & 0.06 & $1.67-16.7$ & $0.075-0.5$ & 0 \\
& 0.12 & $0.83-6.67$ & & 0.01 \\
& 0.18 & $0.42-4.20$ & & 0.02 \\
\hline Circular tank] & & & & \\
$D$ [m] & $d_{i}[\mathrm{~m}]$ & $n[\mathrm{rps}]$ & $H[\mathrm{~m}]$ & $H s_{0}[\mathrm{~m}]$ \\
\hline 0.29 & 0.03 & $5.00-46.7$ & $0.07-0.22$ & 0 \\
& 0.06 & $1.67-16.7$ & & \\
& 0.12 & $0.83-6.67$ & & \\
0.59 & 0.06 & $1.67-16.7$ & $0.14-0.30$ & 0 \\
& 0.12 & $0.83-6.67$ & & \\
& 0.18 & $0.42-4.20$ & &
\end{tabular}




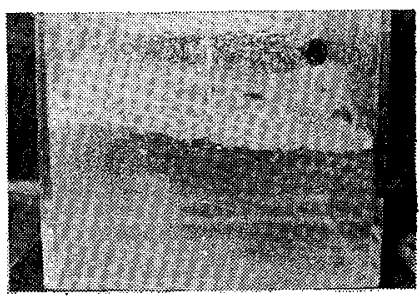

Square tank

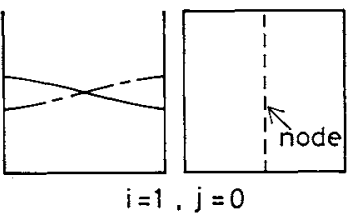

(a) in square tank, $W=0.3 \mathrm{~m}, H=0.15 \mathrm{~m}$, $d_{i}=0.12 \mathrm{~m}, H s_{0}=0 \mathrm{~m}$, $n=3.42 \mathrm{rps}, f=1.61 \mathrm{~s}^{-1}$
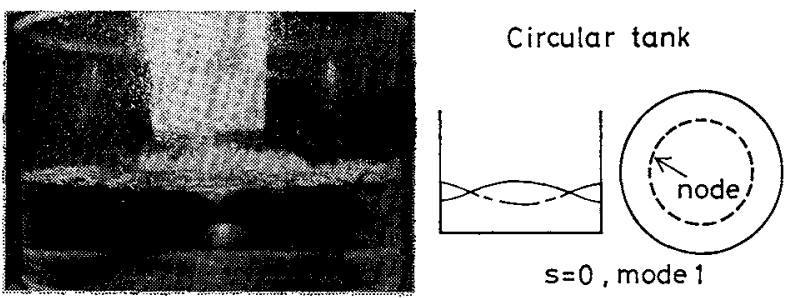

(b) in circular tank, $D=0.59 \mathrm{~m}, H=0.15 \mathrm{~m}$, $d_{i}=0.12 \mathrm{~m}, H s_{0}=0 \mathrm{~m}$, $n=6.67 \mathrm{rps}, f=1.85 \mathrm{~s}^{-1}$
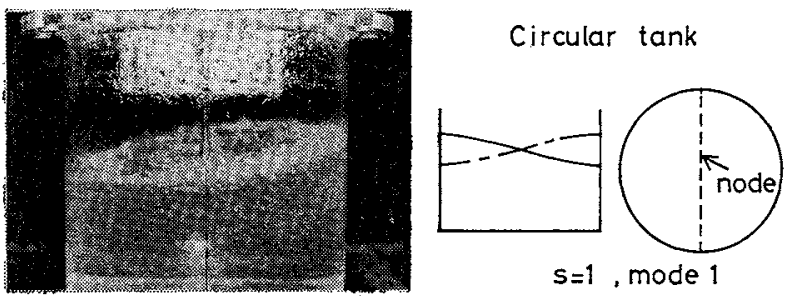

(c) in circular tank, $D=0.29 \mathrm{~m}, H=0.15 \mathrm{~m}$, $d_{i}=0.12 \mathrm{~m}, H s_{0}=0 \mathrm{~m}$, $n=6.67 \mathrm{rps}, f=2.06 \mathrm{~s}^{-1}$

Fig. 2 Standing waves

where $\phi$ is the velocity potential. The boundary conditions for the square tank are

$$
\left.\begin{array}{l}
\left.\frac{\partial \phi}{\partial z}\right|_{z=-H}=0 \\
\left.\frac{\partial \phi}{\partial x}\right|_{x=0, W}=0 \\
\left.\frac{\partial \phi}{\partial y}\right|_{y=0, W}=0
\end{array}\right\}
$$

The frequency of the standing wave $f$ has been given by Lamb ${ }^{2}$ as the solution of Eqs. (1) and (2) as

$$
f=\frac{\sqrt{g k \tanh k H}}{2 \pi}
$$

where $k$ is the wave number. The wave number is given by Eq. (4)

$$
k=\pi \sqrt{\frac{i^{2}+j^{2}}{W^{2}}}
$$

where $W, i$ and $j$ are tank width, $x$ - and $y$-direction oscillation modes, respectively. The oscillation mode observed in the experiment seems to have been the primary one, $i=1, j=0$ or $i=0, j=1$. The theoretical relations calculated by Eqs. (3) and (4) with $i=1, j=0$ are shown in Fig. 3 as well. The theoretical lines

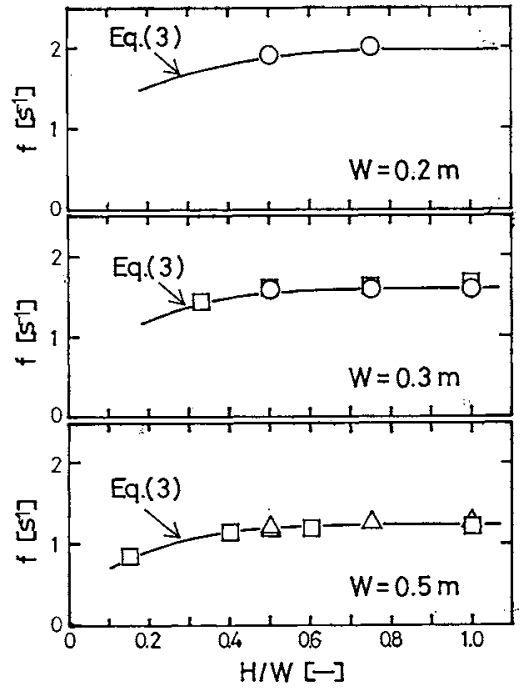

$\left(\bigcirc: d_{i}=0.03 \mathrm{~m}, \square: d_{i}=0.12 \mathrm{~m}, \Delta: d_{i}=0.18 \mathrm{~m}\right)$

Fig. 3 Frequency of standing wave in square tank

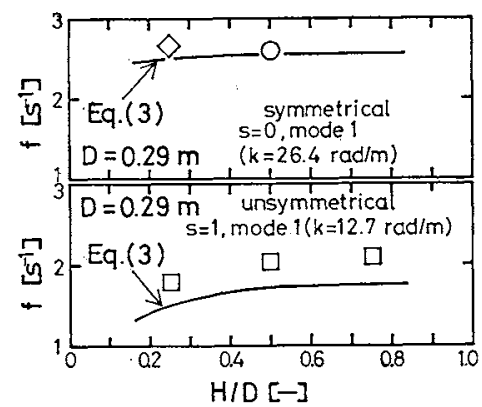

$\left(O: d_{i}=0.03 \mathrm{~m}, \diamond: d_{i}=0.06 \mathrm{~m}, \square: d_{i}=0.12 \mathrm{~m}\right.$ )

Fig. 4 Frequency of standing wave in circular tank

are in good agreement with the experimental results. No other oscillation modes were observed in the square tanks.

In circular tanks two kinds of standing waves, i.e. symmetrical and unsymmetrical standing waves (Fig. 2 (b) and Fig. 2 (c), respectively) were observed. All the standing waves in the circular tanks appeared in the ranges of impeller speed $45.2-46.7 \mathrm{rps}, 11.7-$ $16.7 \mathrm{rps}, 5.00-6.67 \mathrm{rps}$ and $4.67-5.00 \mathrm{rps}$ for impeller diameters $0.03 \mathrm{~m}, 0.06 \mathrm{~m}, 0.12 \mathrm{~m}$ and $0.18 \mathrm{~m}$, respectively. Although the node of the unsymmetrical standing wave rotated in the rotational direction of the impeller, the oscillation phenomena may be analyzed in the same manner. The boundary conditions for the circular tank are

$$
\left.\begin{array}{l}
\left.\frac{\partial \phi}{\partial z}\right|_{z=-H}=0 \\
\left.\frac{\partial \phi}{\partial r}\right|_{r=R}=0
\end{array}\right\}
$$

The wave number for the standing wave in a circular tank is given by Eq. (6). 


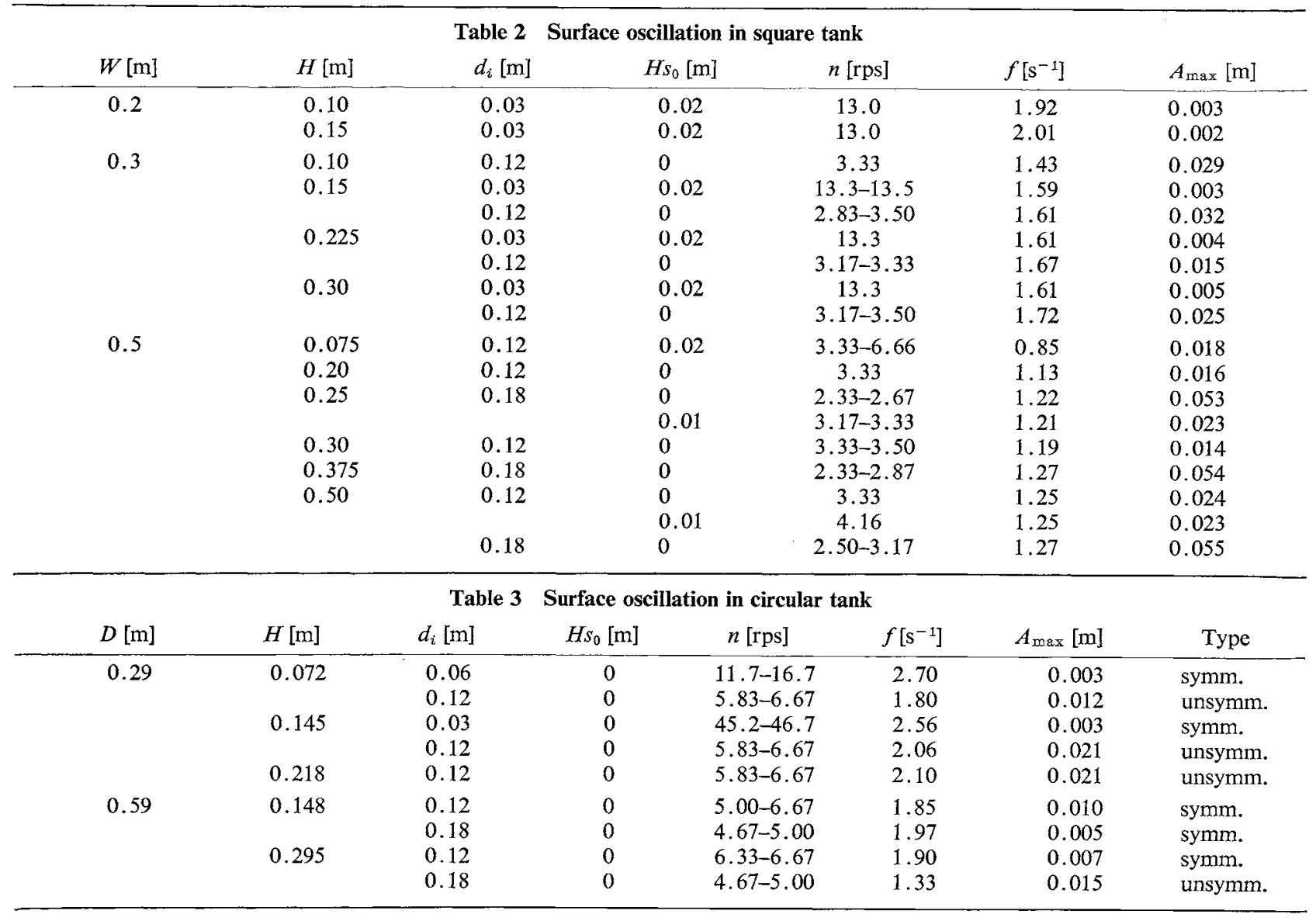

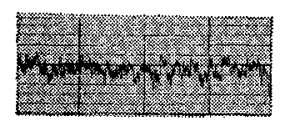

(a) $2.08 \mathrm{rps}$ (no oscillation)

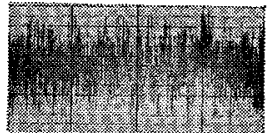

(b) $2.50 \mathrm{rps}$ $\left(\begin{array}{c}\text { oscillation } \\ t=1.27 \mathrm{~s}^{-1} \\ A=0.054 \mathrm{~m}\end{array}\right)$

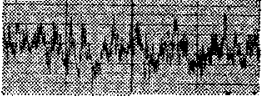

(c) $3.33 \mathrm{rps}$

(no oscillation) (b) is at the condition where standing wave, $i=$ $1, j=0$ or $i=0, j=1$, was observed

Fig. 5 Torque fluctuation on impeller shaft observed in square tank, $W=0.5 \mathrm{~m}, H=0.375 \mathrm{~m}$, $d_{i}=0.18 \mathrm{~m}, H s_{0}=0 \mathrm{~m}$

$$
J_{s}^{\prime}(k R)=0
$$

where $J_{s}(r)$ means the $s$-th Bessel function of the first kind. The frequency of the standing wave for this case is calculated by Eqs. (3) and (6). Figure 4 shows the experimental results of $f$ with the calculated lines by Eqs. (3) and (6). For symmetrical waves, theoretical values are in good agreement with experimental ones for $k=26.4 \mathrm{rad} / \mathrm{m}$. For unsymmetrical waves, there seems to be some difference between theoretical and the experimental values for $k=12.7 \mathrm{rad} / \mathrm{m}$, but the tendency is in fairly good agreement.

The amplitude $A$ of the oscillations observed at the tank wall are summarized in Tables 2 and 3 . It became large with increase of impeller diameter and reached a maximum then decreased. The magnitude of $A$ sometimes became more than $10 \%$ of the tank diameter. This means that if the water mass in the tank is large, the elevation of the water surface will cause damage to the tank and/or impeller. For example, surface oscillation makes the torque on the impeller shaft fluctuate violently. Figure 5 shows examples of the torque fluctuation exerted on the shaft. Figure 5(b) shows a recorded fluctuation of torque under the appearance of the standing wave. The magnitude of torque variation became 2-3 times as large as that for no standing wave, shown in Fig. 5 (a) or (c).

\section{Nomenclature}

$A \quad=$ amplitude of standing wave $[\mathrm{m}]$

$A_{\max }=$ maximum of $A$ [m]

$D \quad=$ diameter of circular tank [m]

$d_{i} \quad=$ diameter of impeller $\quad[\mathrm{m}]$

$f \quad=$ frequency of standing wave $\quad\left[\mathrm{s}^{-1}\right]$

$g \quad=$ gravitational acceleration $\quad\left[\mathrm{m} / \mathrm{s}^{2}\right]$

$H \quad=$ depth of calm water $\quad$ [m]

$H s_{0} \quad=$ impeller submergence from calm water level [m] 


$\begin{array}{ll}i & =\text { oscillation mode of } x \text {-direction } \\ J_{s}(r) & =s \text {-th Bessel function of the first kind } \\ j & =\text { oscillation mode of } y \text {-direction } \\ k & =\text { wave number } \\ l_{b} & =\text { blade length } \\ n & =\text { rotational speed of impeller } \\ R & =\text { radius of circular tank } \\ r & =\text { cylindrical coordinate } \\ W & =\text { tank width of square tank } \\ w_{b} & =\text { blade width } \\ x, y, z & =\text { rectangular coordinate }\end{array}$

$[-]$
$[-]$
$[-]$
$[\mathrm{rad} / \mathrm{m}]$
$[\mathrm{m}]$
$[\mathrm{rps}]$
$[\mathrm{m}]$
$[\mathrm{m}]$
$[\mathrm{m}]$
$[\mathrm{m}]$
$[\mathrm{m}]$
$\theta \quad=$ angle in cylindrical coordinates [rad]
$\phi \quad=$ velocity potential $\quad\left[\mathrm{m}^{2} / \mathrm{s}\right]$

\section{Literature Cited}

1) Akehata, T., H. Unno, Y. Naoki and A. Bernardino: Kogyo Yosui, 237, 24 (1978).

2) Lamb, H.: "Hydrodynamics", 6th ed., p. 440, Cambridge Univ. Press, London (1975).

(Presented in part at the Gumma Meeting of The Soc. of Chem. Engrs., Japan, at Kiryu, 1978.)

\begin{tabular}{|c|c|c|c|c|c|}
\hline \multicolumn{6}{|c|}{ ERRATA TO VOL. 15, NOS. 1-3 (1982) } \\
\hline No. & Page & Column & Line (b: bottom, t: top) & erroneous & should be read \\
\hline \multirow[t]{5}{*}{1} & 59 & $\begin{array}{l}2 \\
2\end{array}$ & $\begin{array}{l}13 b \\
14 b\end{array}$ & $\begin{array}{l}\gamma_{1} \\
\text { ASPG }\end{array}$ & $\begin{array}{l}\gamma_{i} \\
\text { ASOG }\end{array}$ \\
\hline & 60 & 1 & Table 1 & bunary & binary \\
\hline & & & & $\Delta x^{*}$ & $\Delta x_{1}^{*}$ \\
\hline & & & & Phenyl acetic acid & Phenylacetic acid \\
\hline & 61 & 1 & Nomenclature & {$[1.987 \mathrm{cal} / \mathrm{mol} \cdot \mathrm{K}]$} & $1.987[\mathrm{cal} / \mathrm{mol} \cdot \mathrm{K}]$ \\
\hline 2 & 103 & 2 & Fig. 11 & $\times 10^{-5}$ & $\times 10^{5}$ \\
\hline
\end{tabular}

\section{ABSTRACTS OF KAGAKU KOGAKU RONBUNSHU VOL. 8, NO. 5, SEPTEMBER, 1982}

Fracture Mechanism of Virgin Castables during Initial Heating, Masanori Fujitsu and Sachio Sugiyama (Aichi Inst. of Tech.)

Kagaku Kogaku Ronbunshu, 8, 545-551 (1982)

A theoretical analysis to make clear the fracture mechanism of virgin castables during initial heating is performed by the finite element method based on the plane strain model. Comparisons of the calculated results with experimental data for a hollow cylindrical sample without free water resulted in the following findings:

1) The crack detected at the outer surface seemed to result from propagation of the crack which breaks out in the neighborhood of the inner sample surface.

2) Comparisons of the results of this investigation with past studies by the author $e t$ al. showed the same conclusion as the established theory that virgin castables fracture more easily during initial heating than do castables during heating up after the initial heating. The effect of the dehydration reaction of cement hydrate seemed to be negligibly small in this investigation range.

Electrical Measurements of Liquid Diffusion into Organic Linings, Takayuki Iguchi (Nara Tech. Coll.) and Satoshi Okuda (Doshisha Univ.)

Kagaku Kogaku Ronbunshu, 8, 552-555 (1982)

For exact analysis of liquid diffusion into organic linings, the concentration distribution of liquid in the lining was taken into consideration in the calculation of electrical capacitance of the lining, which is increased by liquid diffusion. The results were compared with those obtained in the case of uniform liquid distribution and with the experimental results.

The resistance method to determine the diffusion coefficients was applied to the case in which the decrease in electrical resistance of resin caused by liquid diffusion is relatively small. In this case, the resistance calculation neglecting the electrical resistance of resin without diffusion would have given too crude a result.

Effects of Temperature Gradient on Liquid Diffusion, Rate in Organic Linings, Takayuki Iguchi (Nara Tech. Coll.) and Satoshi Okuda (Doshisha Univ.)

Kagaku Kogaku Ronbunshu, 8, 556-559 (1982)

The degradation process of organic linings where a temperature differential existed was investigated by the application of electrical capacitance measurements. More extensive blistering occurred on linings exposed to hot water on one side and another metallic substrate was kept to a lower temperature. In this case, a large increase in capacitance was measured. This increase of capacitance was due to the penetration of liquid. The liquid diffusion process in linings under a temperature gradient was expressed by introducing the term of thermal diffusion. It was found that thermal diffusion played an important part in degradation of linings under a temperature gradient.

Power Consumption of Surface Aerator in a Square Tank, Hitoshi Takase, Hajime Unno and Takashi Akehata (Tokyo Inst. of Tech.)

Kagaku Kogaku Ronbunshu, 8, 560-565 (1982) 